\title{
The Virtual Mass of Plane Nets*1
}

\author{
Takeshi Yamane*2 and Yunosuke Iitaka*2
}

(Accepted February 10, 1986)

\begin{abstract}
A series of experiments was performed with the purpose of getting the fundamental aspects of the virtual mass effects acting on the net gear motion. Three types of webbings; monofilament with double sheet bend, knotless multifilaments and multifilaments with sheet bend, were used in the experiments. The motion of framed plane nets were recorded as the change in the force through the strain gauge on a recorder. The virtual mass of webbing consisting of multifilament with sheet bend became larger than the other two types. When inclined angle with respect to the moving direction was $0^{\circ}$, the virtual mass represented the maximum value in all cases. The virtual mass effects acting on the mesh size appeared clearly when mesh size became relatively small. The results suggest that the virtual mass of webbing is variable and depends upon the mesh size and the surface shape of webbing in addition to the state of motion.
\end{abstract}

The rigorous solution of the virtual mass effects acting on a fishing gear in oscillatory motion is extremely difficult. The virtual mass of object, as well known, is a function of the size and shape of the body, the direction in which it is moved through the fluid with respect to an axis in the body, and the density and viscosity of the fluid. In the case of net gear placed on a near water surface, such as the gill nets, where it is assumed that the shape of webbing against the moving direction changes due to the magnitude of wave, the virtual mass effects acting on a gear oscillatory motion will become very complex.

The results obtained from the field experiments ${ }^{1,2}$ using actual gill net and the model experiments $^{33}$ in a wave channel indicate the deformation in mesh configuration of webbing is closely related to the catching efficiency of the gear. The deformation in mesh configuration of webbing would be mainly arised from the virtual mass effects acting on a webbing and accessories of a gear. When considering the effective gear planning and rational operation, it is therefore necessary to make clear the virtual mass effects acting on a webbing.

The virtual mass of the object in oscillatory motion had been investigated both analytically and experimentally by many research workers. ${ }^{4-14)}$ In these researches, virtual mass of objects with simple shape such as a sphere, a cylinder and plate etc. were comfirmed rigorously. However, there are few researches ${ }^{15-17)}$ on the virtual mass of porous object. Also, these reports mainly discussed the virtual mass effects acting on porous thin plates. Net webbing can also be regarded as a porous object. However, the results of these researches on the virtual mass may not be applicable to webbing which are easily deformed by wave action.

Although the resistance of objects to accelerating movement in a fluid is an important problem in examining the fishing gear motion, there are few basic experiments on the resistance of a net gear in accelerated motion. Basic research on the virtual mass of webbing is seldom found. In 1964, Miyazaki ${ }^{18)}$ carried out merely an experimental study using a plane net (multifilament with flat knot and with sheet bend) pointing out that the virtual mass of a webbing is approximately 1.0 when considering an ideal fluid situation. However, there are still a number of unclearified points regarding the relations between virtual mass effect on mesh size and inclined angle with respect to the moving direction.

One of the difficulties in evaluating the virtual mass effects acting on a net gear is that the geometrical configuration with respect to the moving direction is changed continuously due to the wave action. The magnitude of virtual mass is a function of the moving direction of object. Since the rigorous evaluation of virtual mass effects acting on a net gear is very complex problem, it seems more practical to start with the simple model such as a plane webbing hung to a rigid frame. The

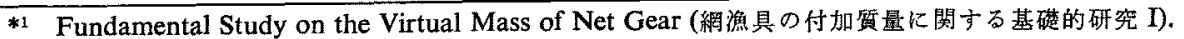

*2 Department of Fisheries, Faculty of Agriculture, Kinki University, Higashiosaka, Osaka 577, Japan (山根 猛, 飯高勇纪助: 近幾大学農学部水産学科). 
Table 1. Dimensions of webbing used in experiments. Polyamide (PA), Polyvinyldene chloride (PVD), Polyethylene (PE), Polyvinyl alcohol (PVAA), Polyvinyl chloride (PVC)

\begin{tabular}{|c|c|c|c|c|c|}
\hline Material & $\begin{array}{l}\text { Kind of } \\
\text { thread used }\end{array}$ & $\begin{array}{l}\text { Diameter of } \\
\text { twine }(\mathrm{cm})\end{array}$ & $\begin{array}{c}\text { Mesh size } \\
\text { (two bars) } \\
\text { (cm) }\end{array}$ & $\begin{array}{l}\text { Dried mass } \\
\text { (g/area of } \\
\text { frame) }\end{array}$ & $\begin{array}{l}\text { Wetted mass } \\
\text { (g/area of } \\
\text { frame) }\end{array}$ \\
\hline \multirow[t]{16}{*}{ PA } & Monofilament & 0.059 & 3.4 & 0.355 & \\
\hline & (double sheet & $" \prime$ & $" 1$ & 0.711 & \\
\hline & bend) & $" \prime$ & $" 1$ & 1.357 & \\
\hline & & $"$ & 6.0 & 0.236 & \\
\hline & & $"$ & $"$ & 1.367 & \\
\hline & & " & $"$ & 1.791 & \\
\hline & & $" \prime$ & $"$ & 2.404 & \\
\hline & & 0.061 & 7.4 & 0.236 & \\
\hline & & $"$ & $"$ & 0.894 & \\
\hline & & $" \prime$ & " & 1.157 & \\
\hline & & $" \prime$ & $"$ & 1.620 & \\
\hline & & 0.056 & 11.2 & 0.728 & \\
\hline & & " & " & 1.289 & \\
\hline & & $" \prime$ & " & 2.297 & \\
\hline & & $"$ & " & 5.668 & \\
\hline & & 0.067 & 12.2 & 1.064 & \\
\hline \multirow[t]{5}{*}{ PVD } & Multifilament & 0.098 & 2.9 & 7.687 & 9.686 \\
\hline & (sheet bend) & ." & $" \prime$ & 11.829 & 14.904 \\
\hline & & $"$ & " & 23.396 & 29.479 \\
\hline & & " & " & 17.444 & 21.979 \\
\hline & & $" r$ & " & 27.560 & 31.873 \\
\hline \multirow[t]{5}{*}{ PA } & & 0.13 & 3.3 & 43.425 & 55.584 \\
\hline & & $" \prime$ & sr & 33.967 & 43.478 \\
\hline & & $" \prime$ & " & 24.502 & 31.362 \\
\hline & & $" \prime$ & " & 16.153 & 20.675 \\
\hline & & $" \prime$ & " & 9.793 & 12.535 \\
\hline \multirow[t]{3}{*}{ PVD } & & 0.19 & 6.0 & 14.141 & 15.559 \\
\hline & & $" \prime$ & $"$ & 16.930 & 18.623 \\
\hline & & $" \prime$ & 11 & 33.477 & 36.825 \\
\hline \multirow[t]{3}{*}{ PE } & & 0.13 & 4.0 & 6.061 & 8.728 \\
\hline & & $" 1$ & $" 1$ & 10.109 & 14.557 \\
\hline & & $" \prime$ & $"$ & 22.824 & 32.866 \\
\hline \multirow[t]{2}{*}{ PA } & & 0.033 & 1.3 & 2.484 & 2.956 \\
\hline & & $" \prime$ & $"$ & 7.217 & 8.588 \\
\hline \multirow[t]{2}{*}{ PVAA } & & 0.10 & 2.8 & 3.748 & 4.161 \\
\hline & & $"$ & $"$ & 7.528 & 8.356 \\
\hline \multirow[t]{2}{*}{ PA } & & 0.16 & 8.4 & 3.685 & 5.380 \\
\hline & & $" \prime$ & $" \prime$ & 9.661 & 14.105 \\
\hline \multirow[t]{2}{*}{ PVD } & & 0.13 & 3.6 & 12.171 & 16.431 \\
\hline & & $" \prime$ & $"$ & 10.409 & 14.052 \\
\hline \multirow[t]{2}{*}{ PVD } & & 0.083 & 2.2 & 3.055 & 4.185 \\
\hline & & $"$ & $"$ & 6.040 & 8.274 \\
\hline \multirow[t]{2}{*}{ PE } & & 0.070 & 3.8 & 1.322 & 1.454 \\
\hline & & " & $"$ & 4.844 & 5.329 \\
\hline \multirow[t]{2}{*}{ PA } & & 0.10 & 4.0 & 2.955 & 3.871 \\
\hline & & " & $"$ & 4.601 & 6.027 \\
\hline \multirow[t]{2}{*}{ PA } & & $"$ & 7.0 & 2.016 & 3.044 \\
\hline & & $" \prime$ & " & 1.208 & 1.824 \\
\hline PA & & 0.15 & 5.0 & 10.779 & 14.875 \\
\hline PE & & 0.16 & 10.7 & 2.238 & 2.842 \\
\hline PVD & & 0.15 & 4.5 & 9.487 & 11.764 \\
\hline $\mathrm{PE}$ & & 0.12 & 2.6 & 9.746 & 13.254 \\
\hline
\end{tabular}


Table 1. (Continued)

\begin{tabular}{|c|c|c|c|c|c|}
\hline Material & $\begin{array}{l}\text { Kind of } \\
\text { thread used }\end{array}$ & $\begin{array}{l}\text { Diameter of } \\
\text { twine }(\mathrm{cm})\end{array}$ & $\begin{array}{c}\text { Mesh size } \\
\text { (two bars) } \\
\text { (cm) }\end{array}$ & $\begin{array}{l}\text { Dried mass } \\
\text { (g/area of } \\
\text { frame) }\end{array}$ & $\begin{array}{l}\text { Wetted mass } \\
\text { (g/area of } \\
\text { frame) }\end{array}$ \\
\hline PA & & 0.15 & 3.5 & 3.265 & 4.016 \\
\hline $\mathrm{PE}$ & & 0.12 & 2.7 & 4.787 & 5.648 \\
\hline \multirow[t]{2}{*}{ PVD } & Multifilament & 0.19 & 14.8 & 6.861 & 8.027 \\
\hline & (knotless) & " & " & 7.719 & 9.031 \\
\hline \multirow[t]{3}{*}{ PVD } & & 0.12 & 5.6 & 8.015 & 9.137 \\
\hline & & $"$ & $"$ & 9.910 & 11.297 \\
\hline & & $"$ & $" \prime$ & 30.166 & 34.390 \\
\hline \multirow[t]{4}{*}{ PVAA } & & 0.11 & 4.2 & 6.682 & 8.689 \\
\hline & & $"$ & $"$ & 7.152 & 9.300 \\
\hline & & $"$ & " & 11.798 & 15.338 \\
\hline & & $"$ & " & 22.109 & 29.522 \\
\hline \multirow[t]{5}{*}{ PVD } & & 0.10 & 1.4 & 7.538 & 9.497 \\
\hline & & $" \prime$ & $"$ & 16.488 & 20.775 \\
\hline & & $"$ & $"$ & 24.252 & 30.558 \\
\hline & & $"$ & $"$ & 28.925 & 36.446 \\
\hline & & $"$ & $"$ & 43.529 & 54.847 \\
\hline \multirow[t]{2}{*}{ PVD } & & 0.11 & 2.2 & 18.986 & 24.302 \\
\hline & & $" \prime$ & $"$ & 30.853 & 39.491 \\
\hline \multirow[t]{3}{*}{ PVD } & & 0.090 & 4.5 & 5.514 & 6.671 \\
\hline & & $"$ & $"$ & 5.789 & 7.005 \\
\hline & & " & $" \prime$ & 10.200 & 12.342 \\
\hline \multirow[t]{4}{*}{ PVD } & & 0.063 & 4.3 & 3.848 & 4.463 \\
\hline & & " & $\not$ & 4.013 & 4.656 \\
\hline & & $"$ & $"$ & 4.577 & 5.310 \\
\hline & & $"$ & ر & 6.037 & 7.002 \\
\hline \multirow[t]{4}{*}{ PVD } & & 0.091 & 3.4 & 7.568 & 9.309 \\
\hline & & " & $"$ & 9.880 & 12.153 \\
\hline & & " & " & 11.299 & 13.898 \\
\hline & & " & $"$ & 20.549 & 25.276 \\
\hline \multirow[t]{4}{*}{ PVC } & & 0.077 & 5.4 & 3.134 & 4.450 \\
\hline & & " & $"$ & 3.211 & 4.560 \\
\hline & & " & $"$ & 3.675 & 5.219 \\
\hline & & $"$ & $"$ & 4.720 & 6.702 \\
\hline \multirow[t]{4}{*}{ PVC } & & 0.071 & 4.6 & 2.953 & 4.016 \\
\hline & & $"$ & $" \prime$ & 3.558 & 4.839 \\
\hline & & " & " & 6.903 & 9.387 \\
\hline & & $"$ & $"$ & 13.627 & 18.533 \\
\hline PA & & 0.031 & 0.74 & 5.143 & 6.121 \\
\hline
\end{tabular}

present research aims at getting more fundamental knowledge on the virtual mass effect acting on the webbing.

\section{Experiment}

Three types of webbing are used as experimental materials; monofilament with double sheet bend, knotless multifilament and multifilament with sheet bend. All materials are commercially produced. The dimensions of each webbing are shown in detail in Table 1 . The experimental apparatus is shown in Fig. 1. The net is spread using several hanging ratios $(0.1-0.5)$ fitly on a brass frame $24 \mathrm{~cm}^{2}$ and $0.3 \mathrm{~cm}$ diameter. This frame was suspended to a strain gauge through a coil spring. The inclined angle $\theta$ against the moving direction of a plane net was changed in four angles $\left(0^{\circ}, 30^{\circ}, 60^{\circ}\right.$ and $\left.90^{\circ}\right)$. As shown in Fig. 1, the net is suspended at an inclined angle of $\theta$ with respect to moving direction. To change the inclined angle to $90^{\circ}, 60^{\circ}, 30^{\circ}$ and $0^{\circ}$, the nets is suspended using a fixed brass triangular frame attached to the corners of net framing producing the desired angle. The coil spring is attached to the apex of the triangular frame. 
Oscillations of the framed plane net and the framework both in water using an experimental tank $(0.5 \mathrm{~m} \times 0.9 \mathrm{~m} \times 1.1 \mathrm{~m}$ deep) and in air were measured through a strain gauge and recorded using an oscillograph at $2 \mathrm{~cm} / \mathrm{sec}$ chart speed.

\section{Results and Discussion}

There are many kinds of definitions about the so-called "virtual mass". In this study, we consider the virtual mass as defined by the difference of the period of oscillations in vaccum and in fluid. All necessary data were arranged through the average value. The evaluation of the virtual mass, $M_{v}$, was calculated using following fundamental relationship equation ${ }^{3,19)}$

$$
\begin{aligned}
& \qquad M_{v}=M\left(\frac{T_{w}{ }^{2}-T_{W}{ }^{2}}{T_{a}{ }^{2}-T_{A}{ }^{2}}\right)-1 \\
& \qquad M^{\prime}=\frac{M_{v}}{V \rho} \\
& R_{p}=\sqrt{\frac{T_{v}{ }^{\nu}}{d^{2}}} \quad \text { where } \quad T_{v}=\sqrt{T_{w}{ }^{2}-T_{W}{ }^{2}} \\
& T_{w}=\text { natural period of a framed plane net in } \\
& \\
& \text { water } \\
& T_{W}=\text { natural period of a frame in water } \\
& T_{a}=\text { period of a framed plane net in air } \\
& T_{A}=\text { period of a frame in air } \\
& M=\text { mass of wet plane net* } \\
& M_{v}=\text { virtual mass of plane net } \\
& M^{\prime}=\text { inertia coefficient } \\
& V=\text { volume of plane net } \\
& d=\text { diameter of wetted twine } \\
& \rho=\text { density of fluid } \\
& \nu=\text { kinematic viscosity } \\
& R_{p}=\text { corresponding Reynolds number } \\
& T_{v}=\text { corresponding period of a plane net in } \\
& \text { water }
\end{aligned}
$$

\section{Nomenclature}

\section{Monofilament (double sheet bend)}

All results are arranged as the inertia coefficient, $M^{\prime}$, through the average value. The variation of $M^{\prime}$ is represented as a function of $R_{p}$ (corresponding Reynolds number). The results are shown in Fig. 2 where the different marks show the corresponding values at different inclined angle $(\theta)$; for $90^{\circ}, 60^{\circ}, 30^{\circ}$ and $0^{\circ}$. It will be observed that the value of $M^{\prime}$ obtained in each inclined angle

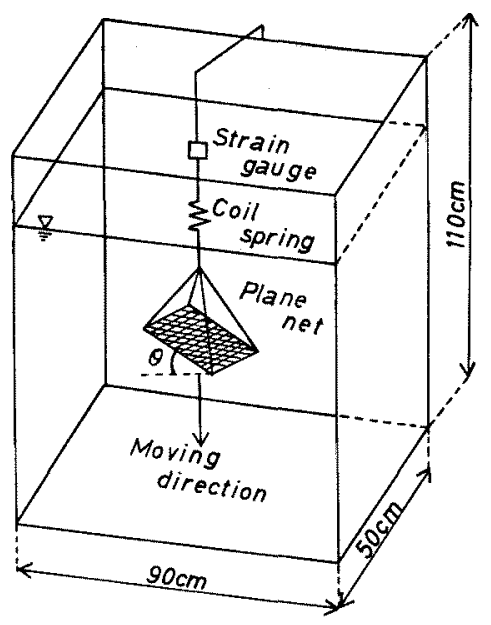

Fig. 1. Setup for the direct measurement of the motion of framed plane net.

becomes large with the increase in the value of $R_{p}$. When considering the difference in the virtual mass of webbing as a results of change in the inclined angle, in this study, we mainly noticed such difference from both $0^{\circ}$ and $90^{\circ}$ inclined angles. The projected area of plane net with respect to the moving direction becomes maximum when $\theta$ is $0^{\circ}$ and it becomes minimum when $\theta$ is $90^{\circ}$. The virtual mass is a function of the moving direction of the object in which it is moved through the fluid with respect to an axis in the body. As is evident from the graph, the value of $M^{\prime}$ obtained in the case of $\theta$ is $0^{\circ}$, reach the maximum value in all cases under the same $R_{p}$. On the other hand, almost of all plots for $\theta=90^{\circ}$ indicate the minimum value. As presented in Fig. 2, since each value of the $y$-intercept for $\theta=0^{\circ}$ is 0.61 and for $\theta=90^{\circ}$ is 0.26 , a value of $M^{\prime}{ }^{\circ} / M^{\prime}{ }_{80^{\circ}}$ is approximately 2.3 .

Fig. 3 demonstrates the relation between $M^{\prime}$ and mesh size. At the same inclined angle, as can be seen in the graph, the value of $M^{\prime}$ becomes almost constant value. This means that the $M^{\prime}$ of monofilament webbing reaches its constant value at each inclined angle given out of relation to the mesh size within the limits of this experiment.

\section{Multifilament (knotless)}

In this case, there are many kinds of materials used as the experimental pieces, therefore in view

* Measure of mass of wet plane net in case of multifilament test piece was prepared by, (1) boiling this webbing for $1 \mathrm{~h},(2)$ immersion in water $\left(1 \mathrm{~m}\right.$ deep) at $20^{\circ} \mathrm{C}$ for $24 \mathrm{~h},(3)$ air exposure at $20^{\circ} \mathrm{C}$ and $75 \%$ humidity for $4 \mathrm{~h}$. 


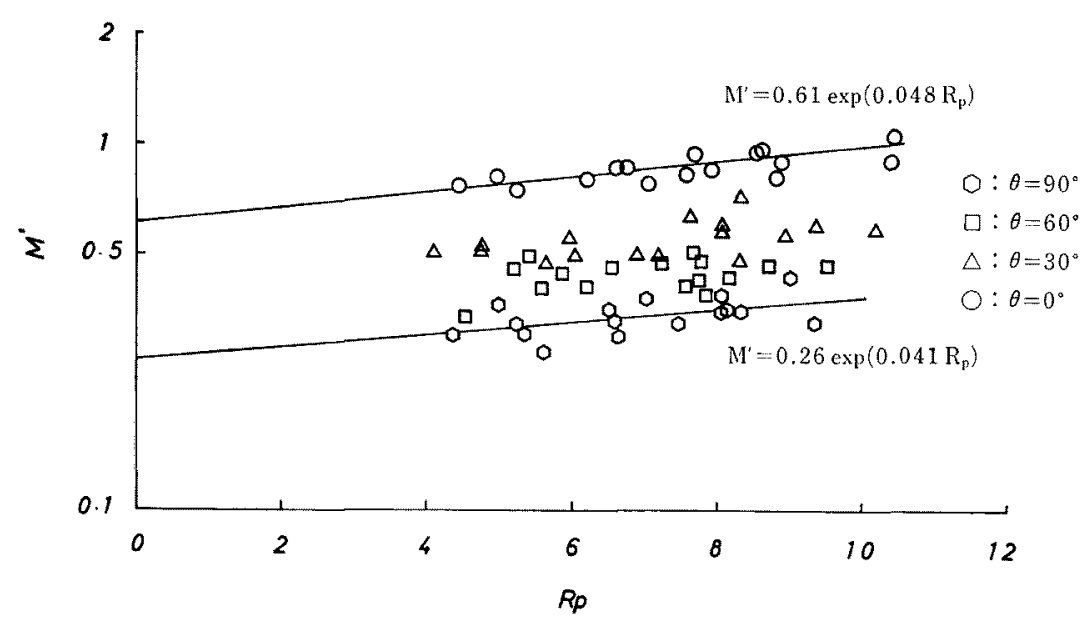

Fig. 2. Relation between the inertia coefficient, $M^{\prime}$ and corresponding Reynolds number, $R_{p}$ for monofilament double sheet bend webbing. Solid lines represent the regression line.

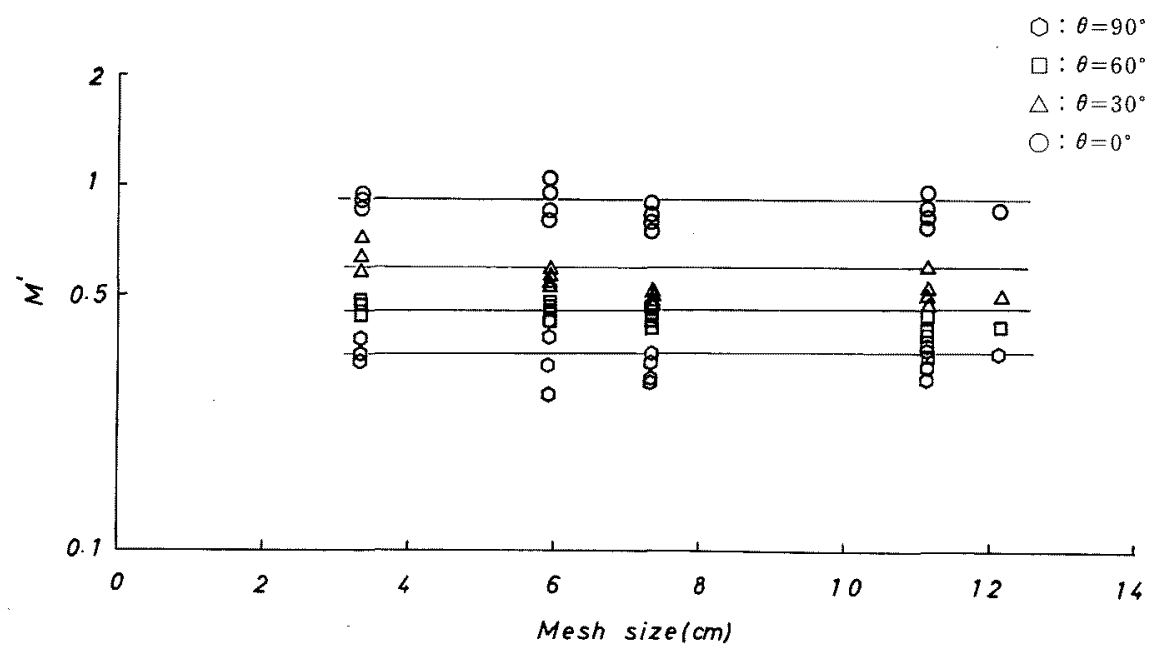

Fig. 3. Relation between the inertia coefficient, $M^{\prime}$ and mesh size for monofilament double sheet bend webbing.

of circumstances of evaluation, the data obtained were arranged into two groups according to the magnitude of suction ratio (mass of wet plane net/mass of dry plane net), $S_{r}$, which indicates the characteristics of material. The first group was ranged at $1.1 \leq S_{r}<1.3$ and the second group was ranged at $1.3 \leq S_{r}<1.5$.

The results obtained for the first group are shown in Fig. 4 as a function of $R_{p}$. As shown in the figure, in case of $\theta=0^{\circ}$, the value of $M^{\prime}$ becomes the maximum value for almost all cases. On the other hand, the plots in the graph for $\theta=90^{\circ}$ indicate minimum value. As can be seen in Fig. 4, the value of $M^{\prime}$ shows the increasing trend due to the increase in $R_{p}$ in all cases. This means that the $M^{\prime}$ can be represented as a function of $R_{p}$. The four plots although separated from the main cluster appear within the projected experimental line. These plots were calculated from the data obtained for the minnow net with smallest mesh size. Since both values of y-intercept are 1.5 for $90^{\circ}$ and 2.8 for $0^{\circ}$, a value of $M^{\prime}{ }^{\prime} / M_{90^{\circ}}^{\prime}$ becomes approximately 1.9 .

Fig. 5 demonstrates the results of second group. Although the plots are slightly scattered, it is seen that the $M^{\prime}$ also shows the increasing trend to the 


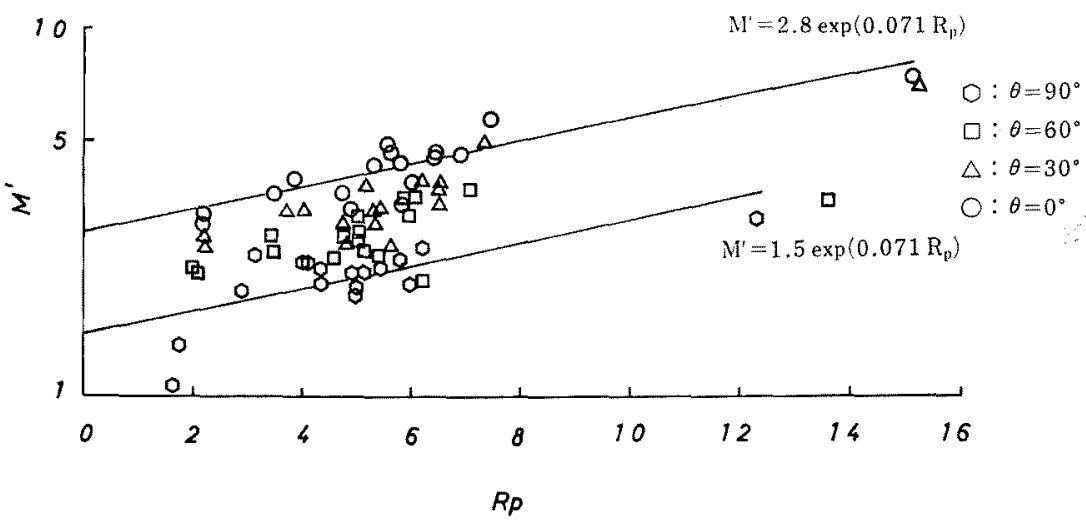

Fig. 4. Relation between the inertia coefficient, $M^{\prime}$ and corresponding Reynolds number, $R_{p}$ for multifilament knotless webbing at $1.1 \leq S_{r}<1.3$. Solid lines represent the regression line.

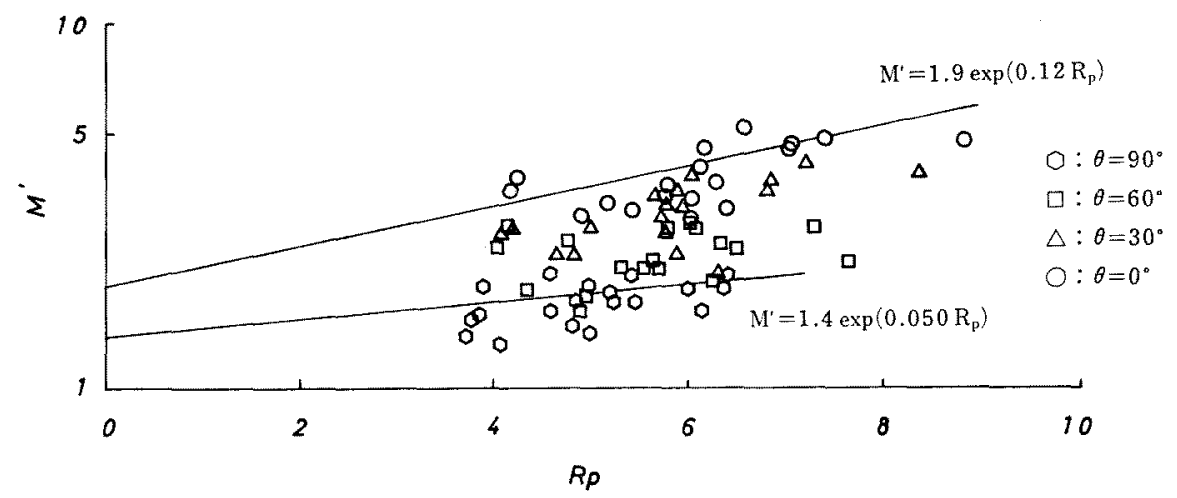

Fig. 5. Relation between the inertia coefficient, $M^{\prime}$ and corresponding Reynolds number, $R_{p}$ for multifilament knotless webbing at $1.3 \leq S_{r}<1.5$. Solid lines represent the regression line.

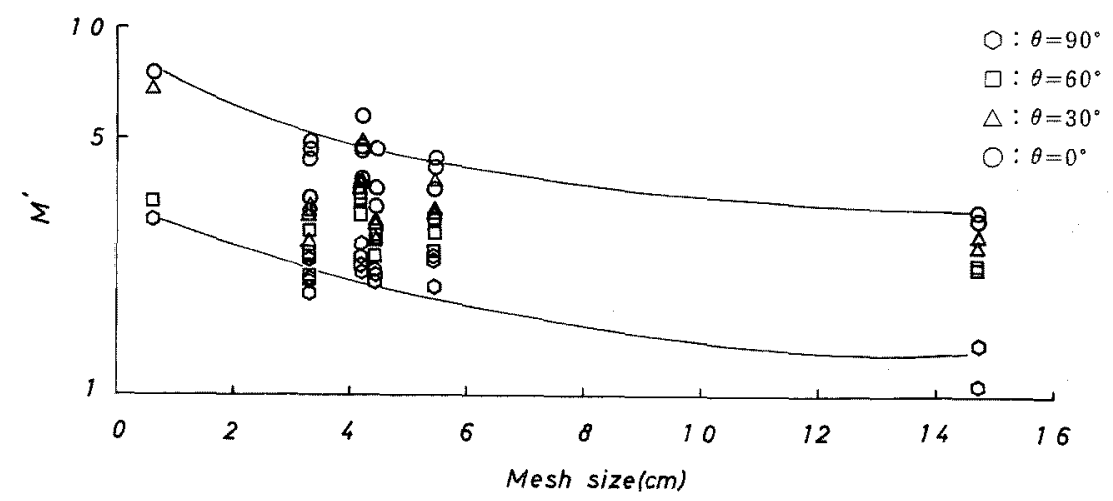

Fig. 6. Relation between the inertia coefficient, $M^{\prime}$ and mesh size for multifilament knotless webbing at $1.1 \leq S_{r}<1.3$.

increase in $R_{p}$. In this case, the ratio of y-intercept for $\theta=90^{\circ}$ and $\theta=0^{\circ}$, the value of $M_{0^{\circ}}^{\prime} / M^{\prime}{ }_{80^{\circ}}$ is approximately 1.4 .

Figs. 6 and 7 demonstrate the relation between
$M^{\prime}$ and mesh size. In the case of first group (Fig. 6), though the experimental values plotted appear partially in the graph within the limits of this experiments, the value of $M^{\prime}$ almost shows 


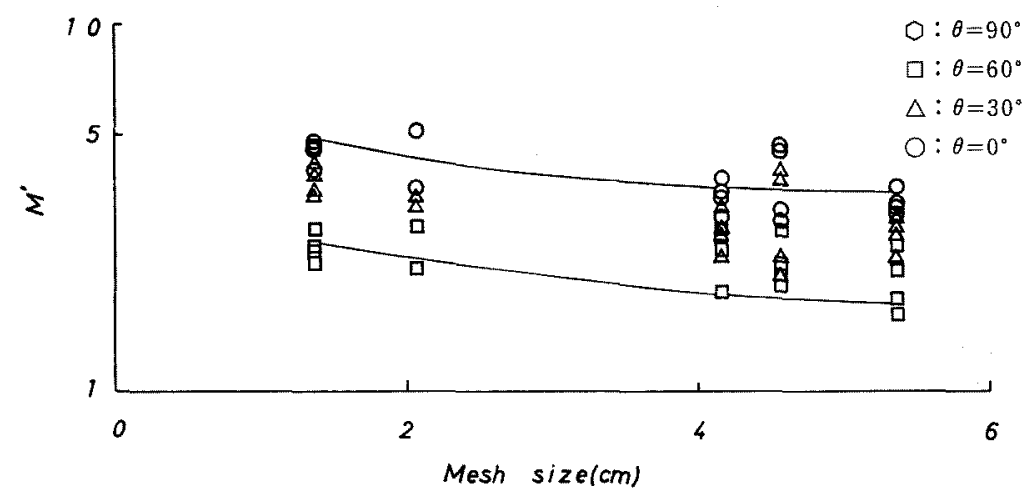

Fig. 7. Relation between the inertia coefficient, $M^{\prime}$ and mesh size for multifilament knotless webbing at $1.3 \leq S_{r}<1.5$.

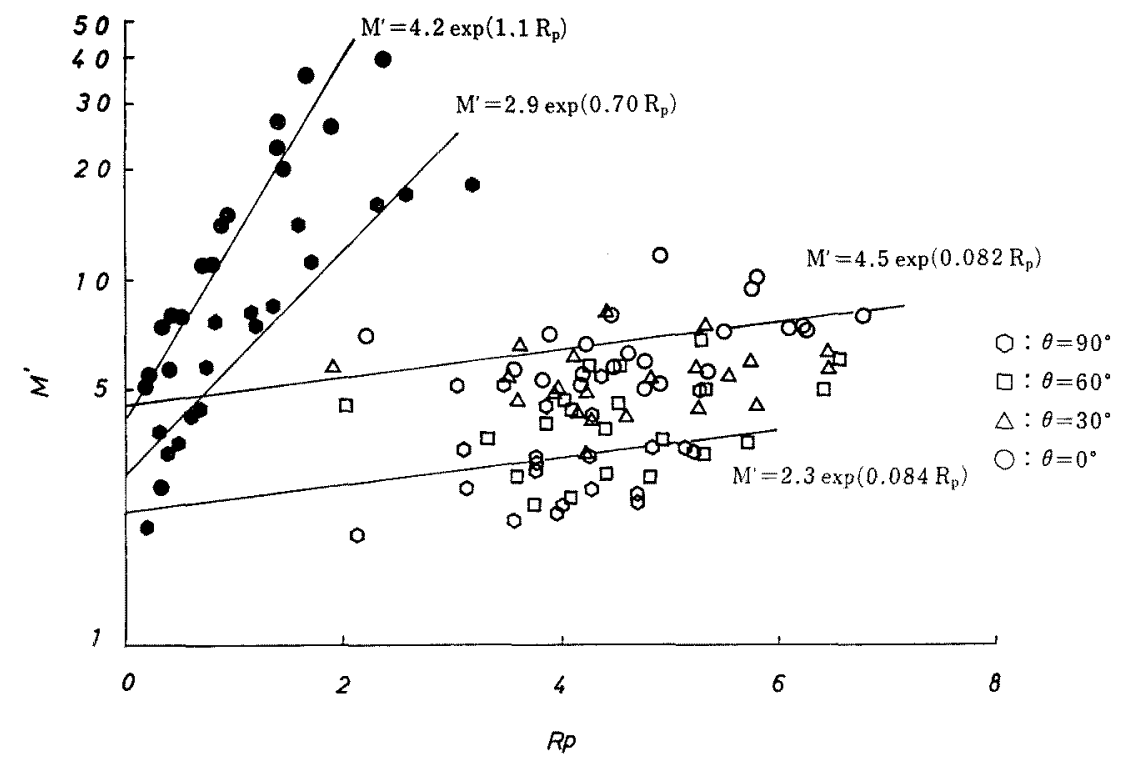

Fig. 8. Relation between the inertia coefficient, $M^{\prime}$ and corresponding Reynolds number, $R_{p}$ for multifilament sheet bend webbing at $1.3 \leq S_{r}<1.5$. Solid line represent the regression line. Closed marks represent the results obtained by Miyazaki.

increasing trend with the decrease in mesh size in all cases. For the second group, as shown in Fig. 7, although the plots were scattered making it difficult to show clear relationship between the size and $M^{\prime}$, as a whole, the $M^{\prime}$ shows an increasing trend with the decrease in mesh size. Though we can not draw the conclusion immediately because of insufficient data, it is presumed that when the webbing consisted of relatively small meshes is oscillated through the fluid, the virtual mass effect acting on this webbing will be con- siderably large.

\section{Multiflament (sheet bend)}

In this case, the results obtained were also arranged into the same range as that provided the experiments using knotless webbing at ranged $1.3 \leq S_{r}<1.5$. Fig. 8 represented the results of $M^{\prime}$ values obtained as a function of $R_{p}$. In Fig. 8 although the plots are slightly scattered, as a whole, the $M^{\prime}$ is clearly defined. The experimental plots for each inclined angle would group 
together with only few exceptions. And as can be seen from the figure, the value of $M^{\prime}$ also increase with the decrease in inclined angle.

Miyazaki ${ }^{18)}$ pointed out that the virtual mass will become considerable large when $R_{p}$ over 1 . His results are also plotted in Fig. 8 using closed marks $(0,0)$. In the present study, when the value of the $y$-intercept for $\theta=0^{\circ}$ is 4.5 and for $\theta=90^{\circ}$ is 2.3 , resulting to the value of $M^{\prime}{ }_{0^{\circ}} / M^{\prime}{ }_{80^{\circ}}$ at approximately 2.0. On the other hand, from Miyazaki's results $M^{\prime}{ }_{0}^{\circ} / M_{80^{\circ}}^{\prime}$ is calculated approximately as 1.4. Although we can not compared directly the results obtained in the present study with his results because of the differences in the experimental conditions, it is assumed that when the value of $R_{p}$ becomes large, the virtual mass of the webbing will become considerably large. In this study, though the value of $M^{\prime}$ appears to be small compared with Miyazaki's results, the difference may be traced to the type of experimental procedure and set up applied. As one can understand from equation (1), measuring condition of wetted mass of webbing affects on the amount of virtual mass, $M_{v}$. However, since the measuring method of wetted mass of webbing was not described in his study, precise solution to the cause could not be obtained.

Fig. 9 shows the relation between mesh size and $M^{\prime}$. Though acculate consideration can not be made because of the plots in the graph are concentrated at the left side, the $M^{\prime}$ value become large at relatively small mesh size.

To investigate the relation between virtual mass, inclined angle and mesh size, the oscillation of the framed plane net was measured. In case of the webbing consisted of the multifilament (knotless and sheet bend) as the above experimental results show, the experimental values are scattered compared with the results obtained from the experiments using monofilaments because of the very complex surface shape of multifilament webbings. Though accurate consideration can not be made because of the above observations, it is presented that the virtual mass of the multifilament webbing with sheet bend will become large compared with others under the same $R_{p}$. As there are differences between the value of $M^{\prime}{ }_{0}^{\circ} / M^{\prime}{ }_{90}^{\circ}$ for monofilament, multifilament (knotless) and multifilament (sheet bend) (ranged from 1.4 to 2.3), it could not be sufficiently made clear the relationship between the virtual mass effectiveness and the inclined angle. However, we want to emphasize the general tendency of the change in the amount of the virtual mass due to the change in the inclined angle.

Let us now consider the relation between virtual mass and mesh size. As shown in Figs. 3, 6, 7 and 9 a conclusion can not be drawn immediately due to an insufficient number of experimental samples. It is assumed that in case of a relatively large mesh size, there are no relationship between mesh size and $M^{\prime}$. However, in case of some particularly small mesh size (minnow net and $1.4 \mathrm{~cm}$ mesh size with sheet bend), since above results show considerable large values compared with the other cases, within the limits of this ex-

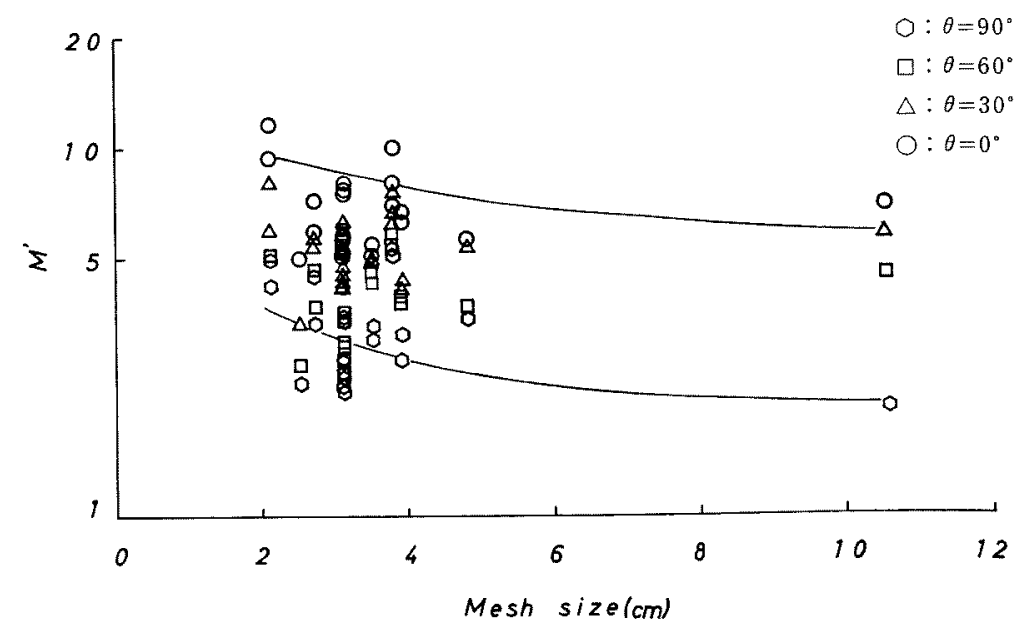

Fig. 9. Relation between the inertia coefficient, $M^{\prime}$ and mesh size for multifilament sheet bend webbing at $1.3 \leq S_{r}<1.5$. 
periment, it is supposed that the virtual mass effectiveness on such webbing will become considerably large.

The results of the experiment is not very clear but it is presumed that both the surface shape of twine and knot, and the shape of webbing with respect to the moving direction have considerable effect on the virtual mass of webbing. To clarify the above situation for multifilament nettings on virtual mass effect, further basic experiment is necessary.

\section{Acknowledgements}

The authors are grateful to Prof. Y. Miyazaki, Tokyo University of Fisheries for useful suggestions. The authors are also thank to Prof. E. E. C. Flores of the University of the Philippines in the Visayas for a critical reading and improving of the manuscript.

\section{References}

1) T. Hamuro: Gyogusokuteiron, Makisyoten, Tokyo, 1959, pp. 247-312 (in Japanese).

2) T. Yamane, K. Nashimoto, K. Yamamoto, and O. Sato: Bull. Fac. Fish. Hokkaido Univ., 32, 169-185 (1981).

3) M. Nomura, K. Mori, and H. Taketomi: Bull.
Japan. Soc. Sci. Fish., 26, 570-576 (1960) (in Japanese).

4) Y. Yamamoto: Rep. Zosenkyokai, 77, 29-41 (1947) (in Japanese).

5) T. Isobe: Appl. Physics, 17, 250-253 (1948) (in Japanese).

6) S. Motora: Rep. Zosenkyokai, 86, 301-308 (1950) (in Japanese).

7) S. Motora: Rep. Zosenkyokai, 87, 47-58 (1951) (in Japanese).

8) H. W. Iversen and R. Balent: J. Appl. Phys., 22, 324-328 (1951).

9) G. H. Keulegan and L. H. Carpenter: J.R.N.B.S., 65, 423-440 (1958).

10) R. Barakat: J. Fluid Mech., 13, 540-556 (1962).

11) W. D. Kim: J. Fluid Mech., 21, 427-450 (1965).

12) J. V. Wehausen: Annual review of Fluid Mech., 3, 237-268 (1971).

13) K. Kudo, A. Kinoshita, and M. Nakato: $J$. Kansaizosenkyokai, 177, 83-90 (1980) (in Japanese).

14) N. Tanaka, Y. Ikeda, Y. Himeno, and Y. Fukutomi: J. Kansaizosenkyokai, 179, 35-43 (1980) (in Japanese).

15) W. K. Meyerhoff: J. Ship Research, 14, 100-111 (1970).

16) W. Koterayama: Rep. Res. Inst. Appl. Mech. Kyushu Univ., 57, 499-514 (1982) (in Japanese).

17) M. Takaki: Rep. Res. Inst. Appl. Mech. Kyushu Univ., 45, 173-188 (1976) (in Japanese).

18) Y. Miyazaki: J. Tokyo Univ. Fish., 50, 159168 (1965) (in Japanese). 